American Journal of Biochemistry and Biotechnology 2 (2): 41-48, 2006

ISSN 1553-3468

(C) 2005 Science Publications

\title{
Nanoceramic Matrices: Biomedical Applications
}

\author{
Willi Paul and Chandra P. Sharma \\ Division of Biosurface Technology, Biomedical Technology Wing, Sree Chitra Tirunal \\ Institute for Medical Sciences \& Technology, Thiruvananthapuram 695012, India
}

\begin{abstract}
Natural bone consisted of calcium phosphate with nanometer-sized needle-like crystals of approximately 5-20 nm width by $60 \mathrm{~nm}$ length. Synthetic calcium phosphates and Bioglass are biocompatible and bioactive as they bond to bone and enhance bone tissue formation. This property is attributed to their similarity with the mineral phase of natural bone except its constituent particle size. Calcium phosphate ceramics have been used in dentistry and orthopedics for over 30 years because of these properties. Several studies indicated that incorporation of growth hormones into these ceramic matrices facilitated increased tissue regeneration. Nanophase calcium phosphates can mimic the dimensions of constituent components of natural tissues; can modulate enhanced osteoblast adhesion and resorption with long-term functionality of tissue engineered implants. This mini review discusses some of the recent developments in nanophase ceramic matrices utilized for bone tissue engineering.
\end{abstract}

Key words: Nanoparticles, Nanomatrices, Bone Tissue Engineering, Oral insulin delivery

\section{INTRODUCTION}

Tissue engineering was defined by Langer and Vacanti ${ }^{[1]}$ as an interdisciplinary field that applies the principles of engineering and life sciences toward the development of biological substitutes that restore, maintain, or improve tissue function. It can also be defined as the use of a combination of cells, engineering materials, and suitable biochemical factors to improve or replace biological functions in an effort to effect the advancement of medicine. The total market for the regeneration and repair of tissues and organs has been estimated to be $\$ 25$ billion worldwide ${ }^{[2]}$. Although transplantation of organs has become an established and successful method of therapy, the severe scarcity of donor organs and immune rejection has become a major limitation and has stimulated the tissue engineering field. The most commonly used materials for encapsulating cells or as scaffolds in tissue engineering are synthetic polymers such as polylactic glycolic acid (PLGA), poly vinyl alcohol (PVA), poly vinyl chloride (PVC), polyacrylonitrile (PAN) etc and natural polymers like alginates, chitosans or collagen and ceramic matrices like calcium phosphates. Two different approaches were being employed in assisted self assembly of cells. In the first approach, donor cells and growth factors were seeded in vitro into the biodegradable scaffold. After the required period for cell growth and multiplication, the scaffold was surgically implanted into the body for the generation of healthy new tissue. In the second approach the scaffold was implanted into the damaged area along with the cells and the growth factors to stimulate tissue regeneration. Scaffolding architecture plays an important role on these three dimensional matrix supports composed of cells and extra-cellular matrix similar to natural tissue organization. Mimicking the natural tissue organization contributes significantly to the biological function of the tissue engineered material. Enormous advances have been made in the field of materials science with the advent of nanotechnology. Bone tissue engineering is a specific area in nanotechnology where the development of nanostructured biomaterials may be able to replace hard and soft skeletal tissue, and biocompatible materials for tissue genesis. Other related areas also include creation of nanoporous biocapsules for cellular therapy. Tissue engineering stands to benefit most from the nanotechnology because of the growing ability to fabricate complex nanostructured materials. This mini review discusses some of the important developments in the utilization of nanoceramic matrices in biomedical technology particularly in tissue engineering.

\section{BIOCERAMICS USED IN BIOMEDICAL TECHNOLOGY}

Calcium phosphate ceramics like hydroxyapatite, tricalcium phosphate and tetracalcium phosphate, alumina, zirconia, silica based glasses or bioactive glasses and also pyrolitic carbons, generally termed as bioceramics, have been used as bone substitutes ${ }^{[3-5]}$. These materials range from inert to bioactive based on their biological activity as they can remain unchanged, dissolve or actively take part in physiological processes to enhance bone tissue formation. Bioactive ceramics

Corresponding Author: Dr. Chandra P. Sharma, Division of Biosurface Technology, Biomedical Technology Wing, Sree Chitra Tirunal Institute for Medical Sciences \& Technology, Poojappura, Thiruvananthapuram 695012. Tel.: 91471 2520214, Fax: 914712341814 
provide a suitable substrate for the attachment of the cells followed by osteogenic differentiation directly on the surface of the ceramic, which results in bone bonding ${ }^{[6]}$. Several studies indicated that growth hormones can stimulate bone growth, collagen synthesis and can effect repair in vivo ${ }^{[7]}$. Scaffolds have been developed containing osteoinductive proteins with and without osteogenic cells utilizing various polymers, ceramics and polymer-ceramic composite towards bone tissue engineering. Ceramics are brittle and not suitable for load bearing applications in the case of orthopedic implants. Numerous studies are being reported on polymer-ceramic composites for improving the mechanical properties to match with the natural loadbearing tissues. Bioactive ceramic materials like tricalcium phosphates, hydroxyapatite and bioglass gained significant importance as scaffolds for bone tissue engineering in recent times. These scaffolds can either induce the formation of bone from the surrounding tissue or can act as a carrier or guide for enhanced bone regeneration by cell migration, proliferation and differentiation ${ }^{[8-10]}$. The main issue regarding the applicability of bioceramics in the filed of bone tissue engineering is its degree of biodegradability (resorption) along with its poor mechanical strength. Nanotechnology can play an important role in this regards to develop porous bioceramics with high mechanical strength and enhanced bioactivity and resorbability ${ }^{[11]}$.

\section{BONE TISSUE ENGINEERING}

The design of biomaterials with surface properties similar to physiological bone that demonstrates the basic criteria of osteoinduction and osteoconduction, promotes formation of new bone and improved orthopedics. Bone tissue engineering is comparatively a new approach in the repair of bony defects. The recent developments of tissue engineering in the field of orthopedic research make it possible to envisage the association of autologous cells and proteins that promote cell adhesion with osteoconductive material to create osteoinductive materials ${ }^{[12]}$. Nature of interaction between osteoblast cells and their substrate can influence the ability of these cells to produce an osteoid matrix around an implant, which in turn will determine the fate of the implant ${ }^{[13]}$. Materials used as a bone tissue engineering scaffold should be biocompatible and porous to be osteoinductive and osteoconductive, and should have the mechanical property compatible with the natural bone tissue. It should also induce cell anchorage and remodel the extracellular matrix in order to integrate with the surrounding tissue $e^{[14,15]}$. The World Health Organization along with 37 countries and United Nations have proclaimed the year $2000-2010$ as the 'Bone and Joint Decade'. This global initiative is intended to improve the lives of people with musculoskeletal disorders, such as arthritis, and to advance understanding and treatment of musculoskeletal disorders through prevention, education and research.

The chemical composition of the tissue engineered scaffold is crucial for the resorbability and osteoconductive properties together with its internal porous structure for the vascular growth. Porous bioceramics hydroxyapatite (HA) and tricalcium phosphate demonstrated to have good osteoconductive properties resulting in a good functional recovery, however, the resorption was poor ${ }^{[16]}$. A novel polymernano hydroxyapatite porous scaffold has been prepared without the use of organic solvents which exhibited significantly higher cell growth, alkaline phosphatase activity, and mineralization in vitro compared to scaffold prepared with organic solvents. Also on implantation, the histological evaluation showed that bone formation was more extensive on scaffold prepared without using organic solvents ${ }^{[17]}$. It has been proposed that the use of culture-expanded osteoprogenitor cells in conjunction with hydroxyapatite bioceramics significantly improves the repair of critical size long bone defects ${ }^{[18]}$. A macroporous hydroxyapatite scaffold coated with PLGA-bioglass demonstrated formation of an apatite layer on sample surfaces immersed in the simulated body fluid (SBF) for 5 days. This also had increased compressive strengths and seems to be a possible scaffold for bone tissue engineering ${ }^{[19]}$. HA ceramic matrices cultured with mesenchymal stem cells (MSCs) obtained from respective patient's bone marrow cells were forced to differentiate into osteoblasts and bone matrix was formed with hydroxyapatite (HA) ceramic. This tissue-engineered HA was used to fill the patient's bone cavity after tumor curettage and exhibited immediate healing potential and has been suggested as an alternative to autologous bone grafts ${ }^{[20]}$. The same has been found effective as 'bone graft' substitute for spinal fusion ${ }^{[21]}$.

\section{NANOTECHNOLOGY IN BIOCERAMICS}

Nanosized hydroxyapatite [HA) is the main component of mineral bone in the form of nanometersized needle-like crystals of approximately 5-20 nm width by $60 \mathrm{~nm}$ length. Synthetic HA possesses exceptional biocompatibility and bioactivity properties with respect to bone cells and tissues, hence have been widely used clinically in the form of powders, granules, dense and porous blocks and various composites. For drug delivery as well as for tissue engineering applications the present trend is to develop new formulations of HA with properties closer to those of living bone, such as nanosized and monolithic structures. Nanophase HA properties such as surface grain size, pore size, wettability, etc, could control 
protein interactions modulating subsequent enhanced osteoblast adhesion and long-term functionality.

Synthetic materials could not be considered as ideal implants as the current average lifetime of an orthopedic implant, such as hip, knee, ankle, etc., is only 15 years. Conventional implants, or those implants constituted with grain size dimensions greater than 1 micron could not invoke natural cellular responses to regenerate tissue that allows longer periods of successful life time. However, since nanophase materials can mimic the dimensions of constituent components of natural tissues, implants developed from nanophase material can be a successful alternative. Several encouraging reports on nanophase materials encourage its use for tissue engineering applications. This has been achieved by the combined effect of its ability to mimic the natural nano dimensions and also the cell responses encouraging high reactivity and in turn helps in regenerating tissues.

NanOss ${ }^{\circledR}$ bone void filer from Angstrom Medica is considered to be the first nanotechnology medical device to receive clearance by the US Food and Drug Administration in 2005. According to the company, NanOss ${ }^{\circledR}$ is an innovative structural biomaterial that is highly osteoconductive and remodels over time into human bone with applications in the sports medicine, trauma, spine and general orthopedics markets. It is engineered synthetic bone developed from nano crystalline calcium phosphate and is the first material that duplicates the microstructure, composition and performance of human bone. Utilizing nanotechnology, calcium and phosphate are manipulated at the molecular level and assembled to produce materials with unique structural and functional properties. It is prepared by precipitating nanoparticles of calcium phosphate in aqueous phase and the resulting white powder is compressed and heated to form a dense, transparent, and nano crystalline material. It is strong and also osteoconductive.

Ostim $^{\circledR}$ is an injectable bone matrix in paste form which received CE marking in 2002. It is composed of synthetic nanoparticulate hydroxyapatite which is indicated for metaphyseal fractures and cysts, acetabulum reconstruction and periprosthetic fractures during hip prosthesis exchange operations, osteotomies, filling cages in spinal column surgery, combination with autogenous and allogenous spongiosa, filling in defects in children etc.

Cell spreading is an essential function of a cell, which has adhered to any surface and precedes the function of cell proliferation. Out of the bone and the ceramic material interactions that take place at the material surface, the interaction of osteoblasts is crucial in determining the tissue response at the biomaterial surface $^{[22]}$. Attachment and spreading of specific bone forming cells in cell culture has been utilized for predicting the behavior of the calcium phosphate materials in $v i v o^{[23]}$. The process of cell interaction on materials is highly dynamic and depends on various parameters influencing the cell responses. It is well known that the size and shape of cell spreading area, as well as the number, size, shape and distribution of focal adhesion plaques are decisive for further migratory, proliferative and differentiation behavior of anchoragedependent cells ${ }^{[24]}$. Cells usually do not survive if the attached cells are round and are not spreading. If the cell material contact area is significantly high the cells tend to skip the proliferation phase and enter sooner the differentiation program. If the adhesion is intermediate the cells are most active in migration and proliferation.

The minerals like zinc and magnesium are know to aid bone growth, calcification and bone density ${ }^{[25,26]}$. Biphasic calcium phosphate ceramic containing zinc also promotes osteoblastic cell activity in vitro ${ }^{[27]}$. The attachment and spreading of osteoblast like cells on to porous ceramic materials made from nanoparticles of zinc phosphate and calcium phosphate containing zinc and magnesium has been evaluated ${ }^{[28]}$. Further, since the ceramic matrices are made from nanoparticles, it mimics the way nature itself lays down minerals. An important objective of bone tissue engineering is to develop improved scaffold materials or arrangement to control osteoblast behavior significantly affecting its response. Osteoblastic cells on hydroxyapatite exhibited unique attachment and subsequent behavior in vitro, which may explain why mineralized tissue formation is better on HA. Divalent cations including $\mathrm{Mg}^{2+}$ are known to be active in cell adhesion mechanisms ${ }^{[29,30]}$. This investigation demonstrated that the cells were spreading well on matrix containing an optimum amount of calcium, zinc and magnesium. It seemed that the presence of calcium and magnesium encouraged the spreading and adhesivity of osetoblasts cells onto bioceramic matrices. Cells were attached and spread completely on the $\mathrm{ZnCaMgP}$ matrix and this matrix appeared to be comparable to the control group (hydroxyapatite matrix) (fig. 1,2). This makes $\mathrm{ZnCaMgP}$ matrix a promising candidate as a bone tissue-engineering scaffold as an alternative to HA.

Nano fibers up to a size range of $240 \mathrm{~nm}$ has been developed based on the sol-gel and electrospinning technique and bioceramic matrices has been developed for possible tissue engineering applications ${ }^{[31]}$. Attempts have been made to culture osteoblasts onto nano hydroxyapatite ceramic matrix. This in vitro cultured bone may show further bone-forming capability after in vivo implantation. This tissueengineering approach is being tried on patients with skeletal problems ${ }^{[32]}$. Adhesion of osteoblast, synthesis of alkaline phosphatase, and deposition of calcium- 
containing mineral increased on poly-lactic-co-glycolic acid (PLGA) scaffolds containing nanophase titania emphasizing the utility of nanotechnology in orthopedic tissue engineering materials ${ }^{[33]}$.

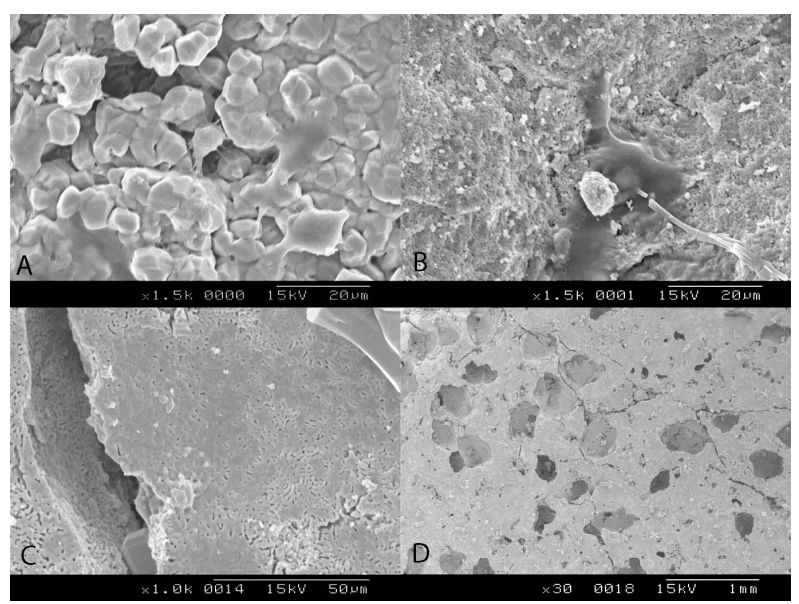

Fig. 1:Osteoblast adhesion on hydroxyapatite matrix (HA) after 24 hours $(\mathrm{A}, \mathrm{B})$ and 5 days $(\mathrm{C}, \mathrm{D})$.

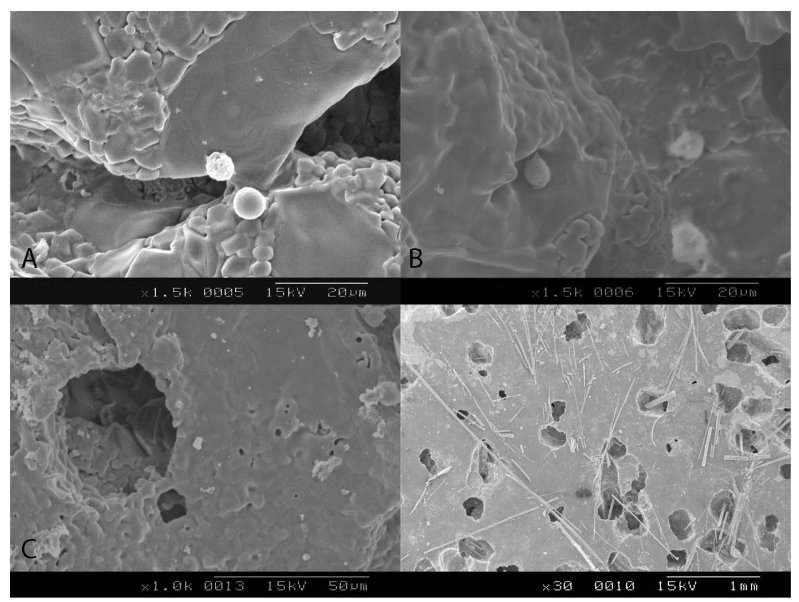

Fig. 2: Osteoblast adhesion on CaZnMgP matrix after 24 hours $(\mathrm{A}, \mathrm{B})$ and 5 days $(\mathrm{C}, \mathrm{D})$.

\section{ORAL INSULIN DELIVERY}

Type I diabetes is characterized by the inefficiency of pancreatic beta cells to produce insulin. The common form of insulin therapy is by way of twice daily subcutaneous insulin injection. Various attempts have been made to develop a non invasive delivery system for insulin namely, via oral, buccal, transdermal delivery routes etc with varying levels of success. It is known that divalent metal cations form complexes with helical phosphates of DNA, which stabilizes the structure. Similarly, the two protein subunits in each insulin molecule will be bound to a single zinc atom with a significant increase in insulin stability. Therefore zinc phosphate nanoparticles could be utilized for attaching insulin and deliver via oral route with suitable $\mathrm{pH}$ sensitive sustained release coating which can protect insulin particles from hydrolysis and enzymatic degradation. We had attempted to develop zinc phosphate particles with average size of $200 \mathrm{~nm}$, attach insulin to these particles and coat with $\mathrm{pH}$ sensitive sodium alginate coating. Zinc phosphate nanoparticles were prepared by precipitation of zinc in a phosphate solution $\left.{ }^{[28,34} 35\right]$. These particles were ultrasonicated for about $15 \mathrm{~min}$ at $100 \mathrm{~W}$. The particles obtained were washed with distilled water and freeze dried. Insulin (Human insulin $400 \mathrm{IU} / \mathrm{ml}$ ) was added to the dry particle and kept overnight for insulin binding at $4^{\circ} \mathrm{C}$. Insulin bound zinc phosphate nanoparticles were centrifuged to remove excess insulin and dried in a refrigerator. Particle size distribution of zinc phosphate nanoparticles is given in figure 3. Particle size ranges from 190 to $295 \mathrm{~nm}$ with a peak diameter of $226 \mathrm{~nm}$.

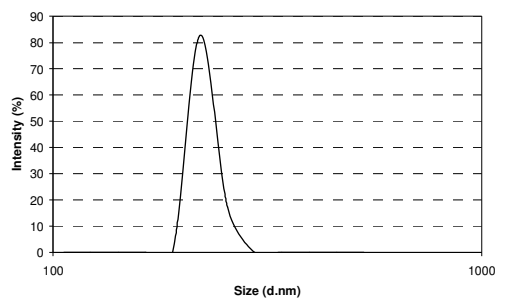

Fig. 3: Particle size distribution of zinc phosphate nanoparticles

Insulin loaded particles were dispersed in $1 \%, 2 \%$ and $4 \%$ solutions of sodium alginate for alginate coating. The size of these coated particles was much bigger and was possibly in the range of 1 micron as observed through an optical microscope. Insulin loading in the 3 formulations was evaluated by extracting the loaded insulin into phosphate buffer $\mathrm{pH}$ 7.4 and estimating the protein content by Lowry's method. The activity of the extracted insulin was evaluated by ELISA technique which was observed as $100 \%$. The drug loading was 23 IU/100mg, 22 IU/100mg and $21 \mathrm{IU} / 100 \mathrm{mg}$ respectively for $1 \%, 2 \%$ and $4 \%$ chitosan coating. The release of insulin in vitro into simulated gastric as well as intestinal medium is shown in figure 4 .

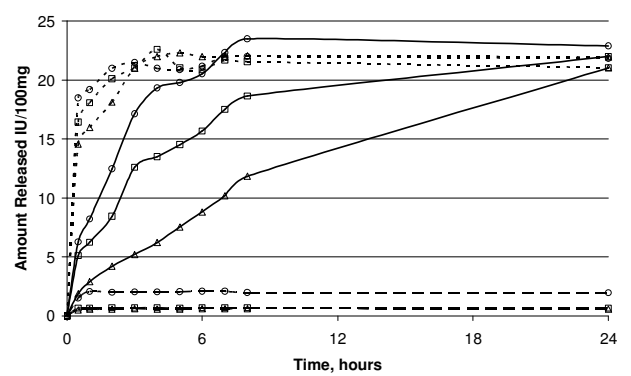

Fig. 4: Amount of insulin released into SGF (pH 1.2, -- -), SIF (pH 6.8, - $\longrightarrow$ ) and SIF (pH 7.4, -----); $1 \%$ - circle, $2 \%$ - square and $4 \%$ triangle.

In the gastric medium the release of insulin was negligible for all coatings and in $\mathrm{pH} 7.4$ the release was 
almost instantaneous with $100 \%$ insulin release in the first 3 hours itself. However, in $\mathrm{pH} 6.8$ (SIF as per USP) the release of insulin was sustained with significant sustenance for $4 \%$ coating. The uptake of particulate carriers by the gastrointestinal epithelium has encouraged number of research groups to investigate nanoparticulate delivery for insulin ${ }^{[36]}$. Translocation of alginate coated zinc phosphate particles through the intestinal lymphatic system may be used as a system for delivering insulin via oral route. In vivo studies need to be completed to evaluate the uptake of particles through the intestinal epithelium. We were able to prepare $\mathrm{pH}$ sensitive ceramic insulin particles from zinc phosphate nanoparticles and demonstrate its release profile in vitro. The result was promising towards its possibility in the development of a non-invasive oral insulin delivery system for diabetes. However, the question of degradability of the ceramic particles is yet to be studied.

Calcium phosphate particles containing insulin was synthesized in the presence of PEG and coated with casein to obtain the calcium phosphate-PEG-insulincasein (CAPIC) oral insulin delivery system. When tested in NOD mice under fasting or fed conditions it was observed that the biological activity of insulin is preserved in CAPIC formulation by protecting insulin from degradation while passing through the acidic environment of the GI track and displayed a prolonged hypoglycemic effect after oral administration ${ }^{[37]}$. Calcium phosphate nanoparticles can also be represented as a unique class of non-viral vector, which can serve as efficient and alternative DNA carriers for targeted delivery of genes. It has been demonstrated that surface modified calcium phosphate nanoparticles can be used in vivo to target genes specifically to the liver ${ }^{[38]}$. Attachment of galactose moiety onto the particle surface has increased the targetability of the particles to the liver. This surface modification makes it possible for site-specific gene delivery.

\section{CERAMIC COATINGS}

Metals like cobalt chromium alloys, titanium and its alloys and Stainless steel 316L are widely used as implants in orthopedic hip and knee surgeries and in dental surgery. Since these are inert materials they may not make a direct bond with the natural tissue. Hydroxyapatite (HA) coating on to these metal implants are known to accelerate bone growth and enhance bone fixation ${ }^{[39]}$. Different methods of HA coatings commercially utilized or being studied are dip coating, sputter coating, pulsed laser deposition, hot isostatic pressing, electrophoretic deposition, sol-gel and thermal spraying. The drawback of most hydroxyapatite-coated implants is that the coating of hydroxyapatite (HA) onto the implants requires elevated processing temperatures or cannot coat complex substrates ${ }^{[40]}$. Biomimetic coating attracted significant attention by researchers because of its advantages over conventional coating as these coating are nanocrystalline and uniform. These coatings, generally composed of octacalcium phosphate (OCP) or carbonate apatite (CA), are suited to complex and porous structure. However, this type of coating process takes significantly long duration and has less bone marrow stromal cell attachment. We have developed a new procedure for coating zinc calcium phosphate nanocrystals onto titanium. These coating are biocompatible as well as antibiotics can be incorporated into these coating to make it antibacterial.

Zinc Calcium Phosphate coating onto cleaned titanium was made by incubating the substrates in a dilute solution of zinc and calcium chloride with an addition of phosphate ions. The nanocrystals are being deposited onto the substrate while the nucleation takes place. Before coating, the titanium was ultrasonically cleaned with acetone, ethanol and distilled water. For the antibiotic incorporation 500mg each of azithromycin and gentamycin was added into the dilute solutions of zinc and calcium chloride. The coatings were observed through an SEM. The antibiotic loading and the release kinetics from the coated surface were evaluated in vitro.

Figure 5 shows the scanning electron micrograph of zinc calcium phosphate coated titanium with a thickness of about 20 microns. A scratch was made on the surface using a diamond tip to evaluate the stability of the coating. A representative scanning electron micrograph of gentamycin loaded zinc phosphate coating is shown in figure 6. Surface morphology of azithromycin loaded and gentamycin loaded coatings were significantly different. Gentamycin loaded coating appears to be porous as compared to azithromycin loaded coating.

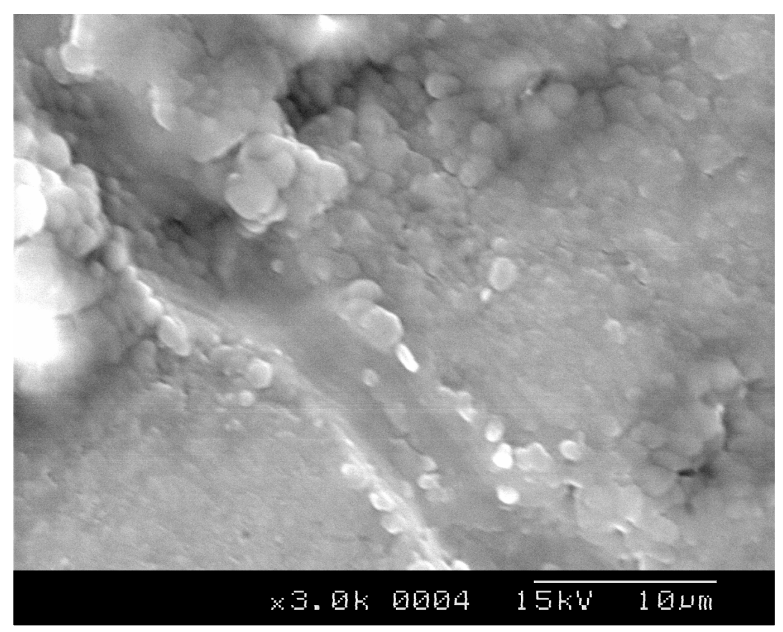

Fig. 5: SEM of the zinc phosphate coated surface scratched with a diamond tip. 


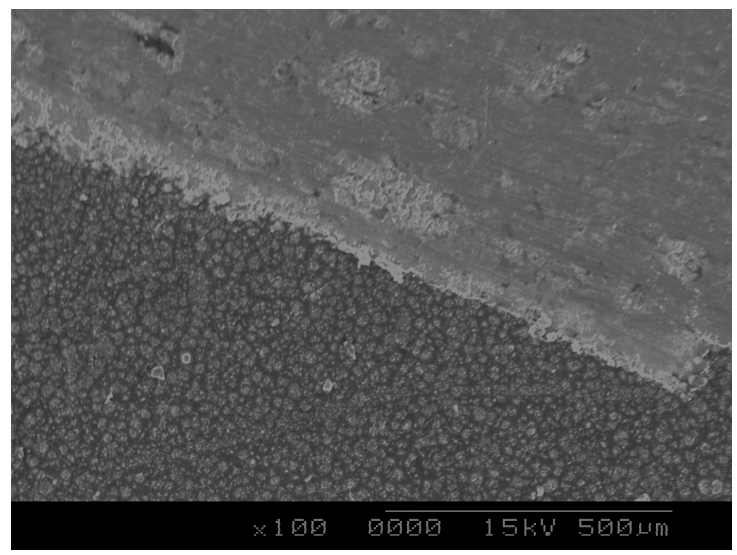

Fig. 6: SEM of the gentamycin loaded zinc phosphate coated surface.

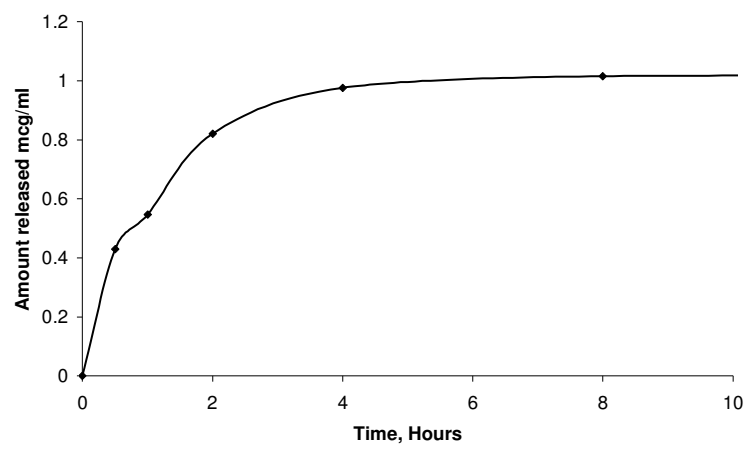

Fig. 7: In vitro release profile of gentamycin from drug loaded zinc calcium phosphate coating on titanium

Porous coating helps in bone cell growth and proliferation on the surface of the implant, resulting in a significantly stronger bond to the parent tissue ${ }^{[41]}$. Consequently, the rate of implant failure would be significantly reduced and the service lifetime of implants will be increased. The amount of drug loaded onto the coating is equivalent to $19.04 \mu \mathrm{g} / \mathrm{cm}^{2}$ for azithromycin and $142.47 \mu \mathrm{g} / \mathrm{cm}^{2}$ for gentamycin. From the in vitro release studies it was observed that the release was sustained up to 8 hours. Efforts are ongoing to increase the drug loading and sustain the drug release to a longer duration. The representative release profile of gentamycin from the coating is shown in figure 7.

Zinc calcium phosphate surface has been shown to be biocompatible by MG-63 osteoblast-like cell adhesion studies $^{[28]}$. It has been shown that antibiotic loaded nanocrystalline coating can be applied onto titanium surface by a new electrolyte coating procedure. Since the coating mineral has been shown to be biocompatible this technique can be utilized to coat complex shaped implant devices to accelerate bone growth and enhance bone bonding. This process can be utilized instead of plasma spraying procedure which is a high temperature procedure. This ceramic coating technique can also be applied to other devices like drug eluting stents if the drug release can be sustained to over 3 to 6 months.

It has been established that nanophase coatings will enhance bone integration and better device fixation. Hydroxyapatite coatings are now widely used for implants; however, it encourages undesirable soft tissue growth along with the desirable hard tissue. Nanophase hydroxyapatite coatings are expected to selectively encourage hard tissue growth. It is reported that some studies has been initiated towards the creation of nanoporous alumina layer on top of a titanium alloy. Mechanical testing showed that the highly adherent nanoporous coating on titanium has a mechanical property similar to that of bone. Helical rosette nanotubes and titania nanotubes are two new approaches for coating on to metallic implants which enhances osteoblast function or helps in efficient nucleation and growth of hydroxyapatite.

\section{CONCLUSION}

Compared to natural human bone, the presently studied polymer scaffolds and ceramic scaffolds have insufficient elastic stiffness and compressive strength. The possible suggested alternative is polymer-cermaic composite and nanocermaic scaffolds which should also have good resorbable properties ${ }^{[42,43]}$. Nano-structured materials or surface coatings will continue to improve the biocompatibility of a growing range of devices and scaffolds for tissue engineered products especially; the work on nanofibrillar networks produced by selfassembly is expected to converge with advances made in cell biology to provide functional scaffolds for tissue engineering applications in the following years to come. Therapeutic approaches for tissue engineered repair of bone defects have attempted to mimic the natural process of bone repair by delivering a source of cells capable of differentiating into osteoblasts, inductive growth and differentiation factors, or bioresorbable scaffolding matrices to support cellular attachment, migration, and proliferation. Nanostructured bioceramics seems to be an ideal matrix for bone tissue engineering since it satisfies all the requirements of a tissue engineered matrix and can be developed into a successful tissue engineered bone during this 'bone and joint decade'.

\section{ACKNOWLEDGMENTS}

We are thankful to the Director, SCTIMST and the Head, BMT Wing for providing facilities for this work.

\section{REFERENCES}

1. Langer, R., and JP Vacanti, 1993. Tissue engineering. Science 260, 920. 
2. 2001. Tissue Engineering: Technologies, Markets, and Opportunities, 3rd Edition, Drug and Market Development Publishing, MA, USA.

3. Mastrogiacomo M, S. Scaglione, R. Martinetti, L Dolcini, F. Beltrame, R. Cancedda, R. Quarto, 2006. Role of scaffold internal structure on in vivo bone formation in macroporous calcium phosphate bioceramics, Biomaterials, 27(17), 3230-3237.

4. Rush SM. 2005. Bone graft substitutes: osteobiologics, Clin Podiatr Med Surg North Am., 22(4), 619-630.

5. Giannoudis PV, H. Dinopoulos, E. Tsiridis, 2005. Bone substitutes: an update, Injury, 36 Suppl 3, S20-27.

6. Hajime O., AI. Caplan, 1999. Stem cell technology and bioceramics: From cell to gene engineering, J. Biomed. Mater. Res. B, 48(6), 913 - 927.

7. Claes O., B. Bengtsson, OGP Isaksson, TT Andreassen, MC Slootweg, 1998. Growth Hormone and Bone Endocrine Reviews, 19(1): 5579.

8. Ramay HR., M. Zhang, 2004. Biphasic Calcium Phosphate Nanocomposite Porous Scaffolds for Load-bearing Bone Tissue Engineering, Biomaterials, 25(21), 5171-5180.

9. Ramay HR., M. Zhang, 2003. Preparation of porous hydroxyapatite scaffolds by combination of the gel-casting and polymer sponge methods, Biomaterials 24(19), 3293-3302.

10. Zhang Y, M. Zhang, 2002. Three-dimensional macroporous calcium phosphate bioceramics with nested chitosan sponges for load-bearing bone implants, J. Biomed. Mater. Res. 61(1), 1-8.

11. El-Ghannam A, 2005. Bone reconstruction: from bioceramics to tissue engineering, Expert Rev Med Devices., 2(1), 87-101.

12. Anselme K., 2000. Osteoblast adhesion on biomaterials, Biomaterials, 21(7), 667-681.

13. Puleo DA, R. Bizios, 1992. Formation of focal contacts by osteoblasts cultured on orthopedic biomaterials, J Biomed. Mater. Res., 26, 291.

14. Scaglione S, A. Braccini, D. Wendt, C. Jaquiery, F. Beltrame, R. Quarto, I. Martin, 2006. Engineering of osteoinductive grafts by isolation and expansion of ovine bone marrow stromal cells directly on 3D ceramic scaffolds, Biotechnol Bioeng., 93(1), 181187.

15. Yoshikawa H, A. Myoui, 2005. Bone tissue engineering with porous hydroxyapatite ceramics. J Artif Organs., 8(3), 131-136.

16. Mastrogiacomo M, A. Muraglia, V. Komlev, F. Peyrin, F. Rustichelli, A. Crovace, R. Cancedda, 2005. Tissue engineering of bone: search for a better scaffold, Orthod Craniofac Res., 8(4), 277284.

17. Kim SS, MS Park, O. Jeon, CC Yong, BS Kim, 2006. Poly(lactide-co-glycolide)/hydroxyapatite composite scaffolds for bone tissue engineering, Biomaterials, 27(8), 1399-1409.

18. Cancedda R, M. Mastrogiacomo, G. Bianchi, A. Derubeis, A. Muraglia, R. Quarto, 2003. Bone marrow stromal cells and their use in regenerating bone, Novartis Found Symp., 249, 133-143.

19. Huang X, X. Miao, 2006. Novel Porous Hydroxyapatite Prepared by Combining $\mathrm{H}_{2} \mathrm{O}_{2}$ Foaming with PU Sponge and Modified with PLGA and Bioactive Glass, J Biomater Appl., [Epub ahead of print].

20. Morishita T, K. Honoki, H. Ohgushi, N. Kotobuki, A. Matsushima, Y. Takakura, 2006. Tissue engineering approach to the treatment of bone tumors: three cases of cultured bone grafts derived from patients' mesenchymal stem cells, Artif Organs, 30(2), 115-118.

21. Tan KK, GH Tan, BS Shamsul, KH Chua, MH Ng, BH Ruszymah, BS Aminuddin, MY Loqman, 2005. Bone graft substitute using hydroxyapatite scaffold seeded with tissue engineered autologous osteoprogenitor cells in spinal fusion: early result in a sheep model, Med J Malaysia., 60 Suppl C:5358.

22. Hunter A, CW Archer, DS Walker, GW Blunn, 1995. Attachment and proliferation of osteoblasts and fibroblasts on biomaterials for orthopedic use, Biomaterials, 16(4), 287-294.

23. Meyer U, A. Büchter, HP Wiesmann, U. Joos, DB Jones, 2005. Basic Reactions of Osteoblasts on Structured Material Surfaces, European Cells and Materials, 9, 39-49.

24. Bačáková L, E. Filová, F. Rypáček, V. Švorčík, V. Starý, 2004. Cell adhesion on artificial materials for tissue engineering, Physiol. Res. 53, s35.

25. Higashi A, T. Nakamura, S. Nishiyama, $M$. Matsukura, S. Tomoeda, Y. Futagoshi, M. Shinohara, I. Matsuda, 1993. Zinc kinetics in patients with bone demineralization due to physical immobilization, J Am Coll Nutr, 12, 61.

26. Tucker KL, MT Hannan, H. Chen, LA Cupples, PWF Wilson, DP Kiel, 1999. Potassium, magnesium and fruit and vegetable intakes are associated with greater bone mineral density in elderly men and women, Am. J. Clin. Nutr., 69, 727.

27. Sogo Y, A. Ito, K. Fukasawa, T. Sakurai, N. Ichinose, 2004. Zinc containing hydroxyapatite ceramics to promote osteoblastic cell activity, Materials Science and Technology, 20, 1079.

28. Paul W., CP Sharma, 2006. Effect of Calcium, Zinc and Magnesium on the Attachment and Spreading of Osteoblast like Cells onto Ceramic Matrices, J. Mater. Sci. Mater. Med., (in press).

29. Fitton, JH, 1995. Divalent Cation Modulation of Cell Adhesion to Surface, In: Proceedings $5^{\text {th }}$ Annual Conference of Australian Soc. Biomater., p.A 22 . 
30. Hynes, RU, 1992. Integrins: Versatility, Modulation and Signaling in Cell Adhesion, Cell, 69, 11.

31. Kim HW, HE Kim, 2005. Nanofiber generation of hydroxyapatite and fluor-hydroxyapatite bioceramics, J Biomed Mater Res B Appl Biomater., [Epub ahead of print].

32. Ohgushi H, J. Miyake, T. Tateishi, 2003. Mesenchymal stem cells and bioceramics: strategies to regenerate the skeleton, Novartis Found Symp., 249:118-127.

33. Webster TJ, TA Smith, 2005. Increased osteoblast function on PLGA composites containing nanophase titania, J Biomed Mater Res A., 74(4), 677-686.

34. Paul W., CP Sharma, 2005. Bioceramics, Towards Nano-enabled Drug Delivery: A Mini Review, Trends Biomat. Artif. Org., 19(1), 7-10.

35. Paul W., CP Sharma, 2001. Porous hydroxyapatite nanoparticles for intestinal delivery of insulin, Trends Biomat. Artif. Org., 14(2), 37-38.

36. Hussain N., V. Jaitley, AT. Florence, 2001. Recent advances in the understanding of uptake of microparticulates across the gastrointestinal lymphatics, Adv. Drug Deliv. Rev., 50, 107-142.
37. Morçöl, P. Nagappan, L. Nerenbaum, A. Mitchell, S.J.D. Bell, 2004. Calcium phosphate-PEG-insulincasein (CAPIC) particles as oral delivery systems for insulin, 2004. Inter. J. Pharm., 277, 91-97.

38. Indrajit R, S. Mitra, A. Maitra, S. Mozumdar, 2003. Calcium phosphate nanoparticles as novel non-viral vectors for targeted gene delivery, Inter. J. Pharmaceutics, 250, 25-33.

39. Clemens JA, CP Klein, RC Vriesde, PM Rozing, K de Groot, 1998. Healing of large (2mm) gaps around calcium phosphate-coated bone implants: a study in goats with a follow-up of 6 months., J Biomed Mater Res, 40, 341-349.

40. Hydroxyapatite coatings an overview, http://www.azom.com/Details.asp?ArticleID=1405 , accessed November 29, 2005.

41. Wilshaw PR, R. Adams, 2003. Mater. World, 11, 16.

42. Boccaccini AR, JJ Blaker, 2005. Bioactive composite materials for tissue engineering scaffolds, Expert Rev Med Devices., 2(3), 303-317.

43. Rezwan K, QZ Chen, JJ Blaker, AR Boccaccini, 2006. Biodegradable and bioactive porous polymer/inorganic composite scaffolds for bone tissue engineering, Biomaterials. [Epub ahead of print] 